\title{
Changes in inflammatory cytokines, antioxidants and liver stiffness after chelation therapy in individuals with chronic lead poisoning
}

Tongluk Teerasarntipan ${ }^{1}$, Roongruedee Chaiteerakij ${ }^{1,2}$, Piyapan Prueksapanich ${ }^{1 *}$ (i) and Duangporn Werawatganon ${ }^{3}$

\begin{abstract}
Background: Chronic exposure to lead causes lead to accumulate mainly in the liver. In vivo studies have shown that lead toxicity is related to alterations in the inflammatory response. We aimed to evaluate the association between lead poisoning and liver fibrosis as well as the change in the degree of liver fibrosis, levels of inflammatory mediators and glutathione (GSH) after chelation therapy.

Methods: Workers from a battery factory who were exposed to lead for $>12$ months and had a blood lead level $(\mathrm{BLL})>70 \mu \mathrm{g} / \mathrm{dL}$ were enrolled $(n=86)$ in the study. Participants underwent chelation therapy with intravenous $\mathrm{CaNa}_{2}$ EDTA for 2 days followed by treatment with oral D-penicillamine for 90 days. The primary outcome was the change in the degree of liver fibrosis, which was presented as liver stiffness (LS) measured by FibroScan ${ }^{\oplus}$. Secondary outcomes were the changes in the levels of serum GSH and inflammatory mediators such as tumor necrosis factoralpha (TNF-a), interleukin-1 $\beta$ (IL-1 $\beta$ ), and interleukin-6 (IL-6) after chelation therapy.

Results: Among the 86 participants, there was a positive correlation between the duration of lead exposure and LS $(r=0.249, p=0.021)$. To avoid the confounding effect of obesity-related steatosis, only 70 individuals who had controlled attenuation parameters $<296 \mathrm{~dB} / \mathrm{m}, \mathrm{BMI}<25 \mathrm{~kg} / \mathrm{m}^{2}$ and normal waist circumference were included in the interventional analysis. After chelation, the mean LS significantly decreased from $5.4 \pm 0.9$ to $4.8 \pm 1.4 \mathrm{kPa}(p=$ 0.001). Similarly, all of the inflammatory cytokines studied significantly decreased after chelation $(p<0.001)$; TNF-a decreased from $371.6 \pm 211.3$ to $215.8 \pm 142.7$; the levels of IL-1 $\beta$ decreased from $29.8 \pm 1.7$ to $25.9 \pm 4.3$; and the levels of IL-6 decreased from $46.8 \pm 10.2$ to $35.0 \pm 11.9$. On the other hand, the mean GSH level increased significantly from $3.3 \pm 3.3$ to $13.1 \pm 3.7(p<0.001)$ after chelation therapy.
\end{abstract}

Conclusion: The duration of lead exposure was significantly correlated with the degree of liver fibrosis. Chelation treatment was associated with increased levels of GSH and decreased levels of proinflammatory cytokines and could potentially reduce the degree of LS.

\footnotetext{
* Correspondence: mpkus1@gmail.com

'Division of Gastroenterology, Department of Medicine, Faculty of Medicine,

Chulalongkorn University and King Chulalongkorn Memorial Hospital, Bangkok 10330, Thailand

Full list of author information is available at the end of the article
}

(c) The Author(s). 2020, corrected publication 2021. Open Access This article is licensed under a Creative Commons Attribution 4.0 International License, which permits use, sharing, adaptation, distribution and reproduction in any medium or format, as long as you give appropriate credit to the original author(s) and the source, provide a link to the Creative Commons licence, and indicate if changes were made. The images or other third party material in this article are included in the article's Creative Commons licence, unless indicated otherwise in a credit line to the material. If material is not included in the article's Creative Commons licence and your intended use is not permitted by statutory regulation or exceeds the permitted use, you will need to obtain permission directly from the copyright holder. To view a copy of this licence, visit http://creativecommons.org/ licenses/by/4.0/. The Creative Commons Public Domain Dedication waiver (http://creativecommons.org/publicdomain/zero/1. 0/) applies to the data made available in this article, unless otherwise stated in a credit line to the data. 
(Continued from previous page)

Trial registration: This study was retrospectively registered and approved by the Thai Clinical Trial Registry (TCTR) on 2019-11-07. The TCTR identification number is TCTR20191108001.

Keywords: Chelation therapy, Chronic Lead poisoning, Hepatic fibrosis, Hepatic Steatosis, Oxidative stress, Hepatotoxicity

\section{Background}

Lead is a heavy metal that can be found in the environment at low concentration levels. However, in the industrialization era, lead is widely used in a variety of products, such as batteries, gasoline, and ceramics [1]. Workers involved in these manufacturing processes are therefore at higher risk of developing lead toxicity. In a recent article, the authors were concerned that the prevalence of lead poisoning was underestimated in lowand middle-income countries [2, 3]. Chronic lead poisoning, although uncommon, is associated with nonspecific symptoms such as constipation, anorexia and recurrent colicky abdominal pain with an insidious onset, and chronic lead poisoning affects multiple organ systems [4]. Hence, many cases are misdiagnosed or detected in late stages.

Most previously reported cases of lead-induced liver injury were associated with mild and self-limited hepatitis. However, limited studies have been conducted in humans that assess the effects of lead poisoning on the liver [5-7]. All previous studies focused on the abnormalities in liver function tests that represented only liver injury at one time point. Since the liver is one of the major reservoirs of lead accumulation, lead poisoning can cause chronic liver injury. Few lead intoxication animal studies have investigated the pathology of liver fibrosis and steatosis. In animal models, a reduction in antioxidants, particularly glutathione (GSH), was identified and was found to be the main mechanism underlying lead-induced hepatoxicity [7]. In addition, it was shown that animals with chronic lead exposure had elevated proinflammatory cytokines, such as interleukin (IL)-1 $\beta$, IL-6, IL-8, IFN- $\gamma$ and tumor necrosis factor (TNF) $-\alpha[7]$.

As a result, the primary aim of our study was to evaluate the effects of chronic lead toxicity on the liver, specifically in regard to fibrosis and steatosis. This study assessed the levels of hepatic fibrosis and steatosis as well as the levels of inflammatory cytokines and antioxidants before and after chelation therapy.

\section{Methods}

\section{Study design}

This study was performed during an initial survey of lead toxicity among individuals who had worked in a battery-manufacturing factory with standard occupational health policies. This study was conducted in two phases. The first phase involved a cross-sectional cohort of participants with severe chronic lead poisoning. We determined the associations between chronic lead poisoning and liver injury. The second phase was a prospective interventional cohort that evaluated whether chelation therapy could reduce lead-related liver injuries. Both studies were conducted from August 1, 2018 to February 1, 2019. In parallel with the study, the lead toxicity prevention program of the factory was re-evaluated and reinforced by occupational medicine specialists to prevent further lead exposure.

\section{Study cohorts \\ Phase I: initial cross-sectional cohort}

This cohort study aimed to evaluate associations between severe chronic lead poisoning parameters and potential adverse effects on the liver. The inclusion criteria were as follows: (1) age $\geq 18$ years; (2) occupational exposure to lead in the battery factory for $\geq 12$ months; and (3) blood lead level (BLL) $\geq 70 \mu \mathrm{g} / \mathrm{dl}$, which is the cut-off level for severe occupational chronic lead poisoning and should be treated with intravenous chelation therapy according to the US Occupational Safety and Health Administration (OSHA) [8]. We excluded participants who had chronic liver diseases such as viral hepatitis $\mathrm{B}$ or $\mathrm{C}$ ( $\mathrm{HBV}$ or $\mathrm{HCV}$ ) infection, autoimmune hepatitis, Wilson's disease, hemochromatosis, or alcoholic liver disease (i.e., history of alcohol consumption $\geq$ $30 \mathrm{~g} /$ day in men or $\geq 20 \mathrm{~g} /$ day in women for at least 3 months within 1 year prior to enrollment) and nonalcoholic fatty liver disease (NAFLD). Participants who had risk factors for NAFLD, such as diabetes mellitus, serum triglycerides $\geq 200 \mathrm{mg} / \mathrm{dL}$, and/or waist circumference (WC) $\geq 102 \mathrm{~cm}$ in men or $\geq 88 \mathrm{~cm}$ in women, were also excluded. Other exclusion criteria were use of possible hepatotoxic medication within 12 months prior to study enrollment, previous chelation therapy, and presence of signs or symptoms of acute lead poisoning such as colicky abdominal pain, hemolytic anemia, and polyneuropathy.

All workers from the battery factory were screened for BLL $(n=720)$. Participants who met the inclusion and 
exclusion criteria were enrolled in the initial crosssectional cohort $(n=86)$.

\section{Phase II: prospective interventional cohort}

This interventional cohort aimed to evaluate the mechanisms underlying liver injury caused by chronic lead poisoning by comparing the change in liver stiffness (LS) and amount of hepatic fat based on the changes in the amount of GSH and proinflammatory cytokines. Since fatty liver is a well-known factor that contributes to liver fibrosis, we excluded 16 participants with severe fatty liver, which is defined as having controlled attenuation parameters $(\mathrm{CAP})>296 \mathrm{~dB} / \mathrm{m}$ or high-risk features for metabolic syndrome such as $\mathrm{BMI}>25 \mathrm{~kg} / \mathrm{m}^{2}$ and $\mathrm{WC}>$ than the cut-off criteria for metabolic syndrome according to the National Cholesterol Education Program Adult Treatment Panel III (NCEP ATP III) (i.e., WC > $80 \mathrm{~cm}$ for women and $\mathrm{WC}>90 \mathrm{~cm}$ for men) to eliminate the effects of confounding factors for obesity-related steatosis. The remaining 70 eligible participants were then enrolled in the prospective interventional cohort. The participants received $2 \mathrm{~g}$ of $\mathrm{CaNa}_{2}$ EDTA intravenously for 2 days followed by $1 \mathrm{~g} /$ day oral D-penicillamine for 90 days. The treatment regimen was a modified regimen designed by our institute's clinical toxicologist in accordance with the drug profiles and patients' medical adherence. All participants were advised to avoid potential hepatotoxic medications and alcohol consumption. The primary outcome was the change in LS and steatosis after chelation therapy. The levels of GSH and inflammatory cytokines were prospectively evaluated on the last day of treatment. Secondary outcomes were the correlations among the change in BLL, liver steatosis, liver fibrosis, GSH and inflammatory markers between the pre- and postchelation therapy timepoints. The investigators and the participants were blinded to the results of the blood tests and FibroScan ${ }^{\circ}$ (Echosens, Paris, France).

\section{Data and specimen collection}

Clinical information, complete blood count, liver function test, and serum samples were collected upon admission. Noninvasive liver assessments were performed by a certified single operator. FibroScan ${ }^{\bullet}$ (transient elastography (TE)) was used to assess liver stiffness (LS) and the degree of liver steatosis, which was presented as controlled attenuation parameters (CAPs).

Serum samples from pre- and postchelation were stored at $-80^{\circ} \mathrm{C}$ until analysis. The levels of GSH, TNF$\alpha$, IL- $1 \beta$, and IL- 6 were measured using a solid-phase enzyme immunoassay technique using commercially available kits (R\&D Systems, Inc., Minneapolis, MN, USA) according to the manufacturer's protocol. The absorbance was read at $450 \mathrm{~nm}$. The flow of the study is shown in Fig. 1.

\section{Statistical analysis}

For testing differences between two dependent means, the estimated sample size was based on the results of a pilot study of 10 workers with chronic lead poisoning that was performed at our hospital; the mean LS was $5.2 \pm 0.7 \mathrm{kPa}$. The reference value of $5.5 \pm 3.8 \mathrm{kPa}$ in the control group was derived from a survey among 782 healthy Thai volunteers [8]. The calculated minimum sample size was 58 cases for $80 \%$ power. Categorical data were compared using Fisher's exact test. Continuous variables are described as the means and standard deviations. Potential relationships between lead-related parameters and the degree of hepatic fibrosis and steatosis were initially assessed using Pearson's correlation analysis. Statistically significant parameters were subsequently included in the multivariate linear regression analysis. A dependent samples t-test was used to compare the results between pre- and posttreatment. Pearson's correlation analysis was used to find the correlation between the percentage changes in BLL and the percentage changes in the levels of inflammatory biomarkers.

\section{Results \\ Phase I: initial cross-sectional cohort Baseline characteristics}

BLL was screened in a total of 720 participants. A total of 180 participants had a BLL $>40 \mu \mathrm{g} / \mathrm{dl}$. This level indicated that chronic lead toxicity was present and that chelation therapy was required (Fig. 1). Among the 180 participants, 86 participants met the inclusion and exclusion criteria and were enrolled in the study. Table 1 shows the baseline characteristics of the 86 participants. Most of the participants were males $(n=71,85 \%)$, and the average age was $37.6 \pm 7.3$ years. The mean BLL was $81.4 \pm 9.8 \mu \mathrm{g} / \mathrm{dl}$. Twenty-six (30.2\%) participants had hepatitis; they had SGOT levels above the ULN ( $>35$ $\mathrm{mg} / \mathrm{dl}, n=14)$ and/or SGPT above the ULN $(>40 \mathrm{mg} / \mathrm{dl}$, $n=17)$.

The mean LS value of the 86 participants was $5.4 \pm$ $0.9 \mathrm{kPa}$. Notably, 23 participants $(26.7 \%)$ from this cohort had significant fibrosis (i.e., the LS value was > $6.1 \mathrm{kPa}$ ). The mean CAP was $225.1 \pm 49.3 \mathrm{~dB} / \mathrm{m}$. Fortyfour $(51.2 \%)$ of the participants had CAP $>213 \mathrm{~dB} / \mathrm{m}$, indicating that there was significant liver steatosis. Among those with significant fibrosis, 42 participants (48.8\%) had no steatosis (S0), while $30(34.8 \%)$ and 15 (17.4\%) participants had mild-moderate steatosis (S1-2) and severe steatosis (S3), respectively. The numbers of participants with LS and CAP are shown in Fig. 2. 
Occupational lead-exposed workers in a battery manufacturing factory were screened for BLL $(n=720)$

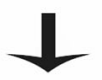

Participants with BLL $>40 \mu \mathrm{g} / \mathrm{dl}$ were assessed for eligibility ( $\mathrm{n}=180)$

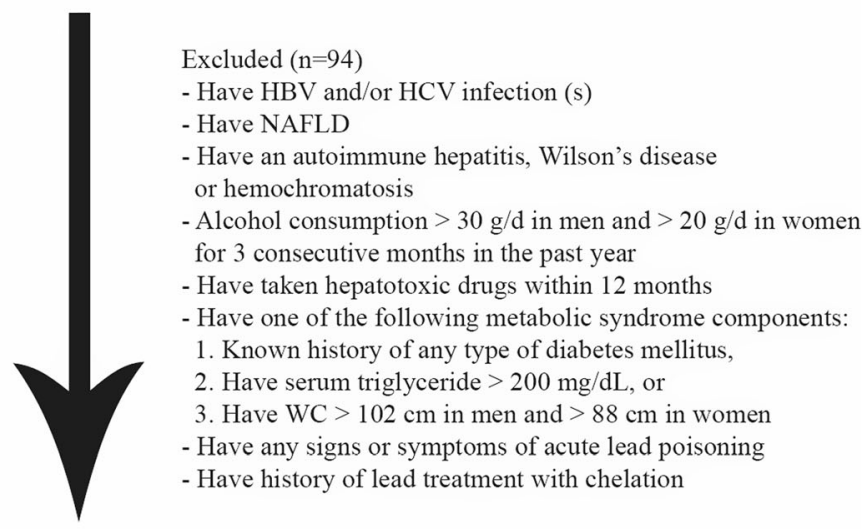

Phase I: Initial cross-sectional cohort $(n=86)$

Associations between chronic lead poisoning (BLL and lead exposure duration) and chronic liver injuries (LFT, TE and CAP)

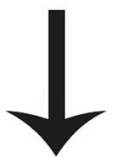

Excluded $(\mathrm{n}=16)$

$\mathrm{CAP}>296 \mathrm{~dB} / \mathrm{m}$ or have high risk features of metabolic syndrome

(BMI $>25 \mathrm{~kg} / \mathrm{m}^{2}$, and $\mathrm{WC}>80 \mathrm{~cm}$ for women and $>90 \mathrm{~cm}$ for men)

Phase II: Prospective interventional cohort $(n=70)$

Chelation therapy was administered to the participants.

The primary outcome was LS (TE).

Secondary outcome: BLL, CAP, LFT, GSH, TNF- $\alpha$, IL-1 $\beta$ and IL-6

Fig. 1 Study flow

\section{Factors associated with liver fibrosis and steatosis}

In the univariate analysis, the duration of lead exposure, but not BLL, was significantly associated with the degree of hepatic fibrosis (Pearson's $\mathrm{r}=0.249, p=$ 0.021). Other factors associated with liver fibrosis included age, BMI, liver steatosis, SGPT, and ALP (Table 2). In the multivariate analysis, only the duration of lead exposure and the SGPT level remained independently associated with liver fibrosis, with Pearson's $\mathrm{r}$ values of 0.229 and $0.317(p=0.026$ and 0.002 ), respectively.

The following variables were found to be significantly associated with the presence of liver steatosis in the univariate model: sex, WC, BMI, liver fibrosis, SGOT, and SGPT. WC and SGPT were independently associated with liver steatosis, with Pearson's $\mathrm{r}$ values of 0.524 and $0.397 \quad(p<0.001$ and 0.018$)$, respectively. We did not detect any association between lead-related parameters and liver steatosis (Table 2).
Phase II. Interventional prospective cohort Effects of chelation therapy on liver fibrosis and steatosis An association between liver fibrosis and steatosis was detected in our initial cross-sectional cohort (Pearson's $\mathrm{r}=0.242, p=0.025)$. After excluding participants with severe fatty liver and those with high-risk features for metabolic syndrome as described previously, a total of 70 participants were enrolled in this study. Correlation analyses were repeated to confirm the independent effects between the degree of liver fibrosis and steatosis. We found that there was no significant association between the degree of fibrosis and steatosis. The Pearson's $r$ between the level of LS and CAP at the prechelation phase was $-0.039(p=0.75)$, and at the postchelation phase, it was $0.151(p=0.21)$. Pearson's correlation analysis between the degree of postchelation LS reduction and the degree of postchelation CAP reduction was $0.160(p=0.19)$ (Supplementary Table 1).

After 3 months of chelation therapy, the mean BLL decreased from $81.8 \pm 9.9$ to $56.6 \pm 16.8 \mu \mathrm{g} / \mathrm{dL}$ (30.8\%). 
Table 1 Baseline pretreatment laboratory profiles of 86 participants in the initial cross-sectional cohort

\begin{tabular}{ll}
\hline Parameters & Mean $\pm \mathrm{SD}$ \\
\hline Age (years) & $37.6 \pm 7.3$ \\
Waist $(\mathrm{cm})$ & $80.2 \pm 12.0$ \\
BMI $\left(\mathrm{kg} / \mathrm{m}^{2}\right)$ & $24.2 \pm 4.9$ \\
Blood lead level $(\mu \mathrm{g} / \mathrm{dL})$ & $81.4 \pm 9.8$ \\
Hemoglobin $(\mathrm{g} / \mathrm{dL})$ & $13.4 \pm 1.6$ \\
White blood cell count $\left(10^{3} / \mathrm{hL}\right)$ & $8.0 \pm 1.8$ \\
Platelets $\left(10^{12} / \mathrm{L}\right)$ & $285.6 \pm 58.4$ \\
Creatinine $(\mathrm{mg} / \mathrm{dL})$ & $0.9 \pm 0.3$ \\
Total bilirubin $(\mathrm{mg} / \mathrm{dL})$ & $0.8 \pm 0.4$ \\
Direct bilirubin $(\mathrm{mg} / \mathrm{dL})$ & $0.3 \pm 0.1$ \\
Alkaline phosphatase $(\mathrm{U} / \mathrm{L})$ & $68.8 \pm 19.5$ \\
SGOT $(\mathrm{U} / \mathrm{L})$ & $30.7 \pm 28.9$ \\
SGPT $(\mathrm{U} / \mathrm{L})$ & $33.3 \pm 33.2$ \\
Liver stiffness $(\mathrm{kPa})$ & $5.4 \pm 0.9$ \\
CAP (dB/m) & $225.1 \pm 49.3$
\end{tabular}

Abbreviations: SGOT serum glutamate oxaloacetate transaminase, SGPT serum glutamate pyruvate aminotransferase, CAP controlled attenuation parameters
After treatment, the degree of LS decreased significantly from $5.33+0.9$ to $4.8+1.4 \mathrm{kPa}(p=0.001)$. We did not find significant improvement in liver steatosis after chelation therapy (mean pre- and postchelation CAP levels were $208.6 \pm 31.7$ and $207.0 \pm 45.0 \mathrm{~dB} / \mathrm{m}, p=$ 0.738 , respectively) (Table 3 ).

\section{Effects of chelation therapy on oxidative stress and inflammatory markers}

The mean levels of the inflammatory biomarkers TNF- $\alpha$, IL- $1 \beta$ and IL- 6 were significantly reduced after chelation therapy by $41.93 \%(371.6 \pm 211.3$ to $215.8 \pm 142.7 \mathrm{pg} /$ $\mathrm{mL}), 13.09 \%(29.8 \pm 1.7$ to $25.9 \pm 4.3 \mathrm{pg} / \mathrm{mL})$, and $25.21 \%(46.8+10.2$ to $35.0 \pm 11.9 \mathrm{pg} / \mathrm{mL})$, respectively. On the other hand, the mean GSH level significantly increased after chelation therapy from $3.3 \pm 3.3$ to $13.1+3.7 \mu \mathrm{g} / \mathrm{mL}$ (297.0\%) (Table 3). However, the correlation between the degree of change in BLL and the reductions in TNF- $\alpha$ and IL- 6 levels was not significant. The increase in the level of GSH was also not significant (Table 4).

\section{Discussion}

Each day, approximately $0.1-2 \mathrm{mg}$ of lead enters the human body through ingestion (75\%), inhalation and

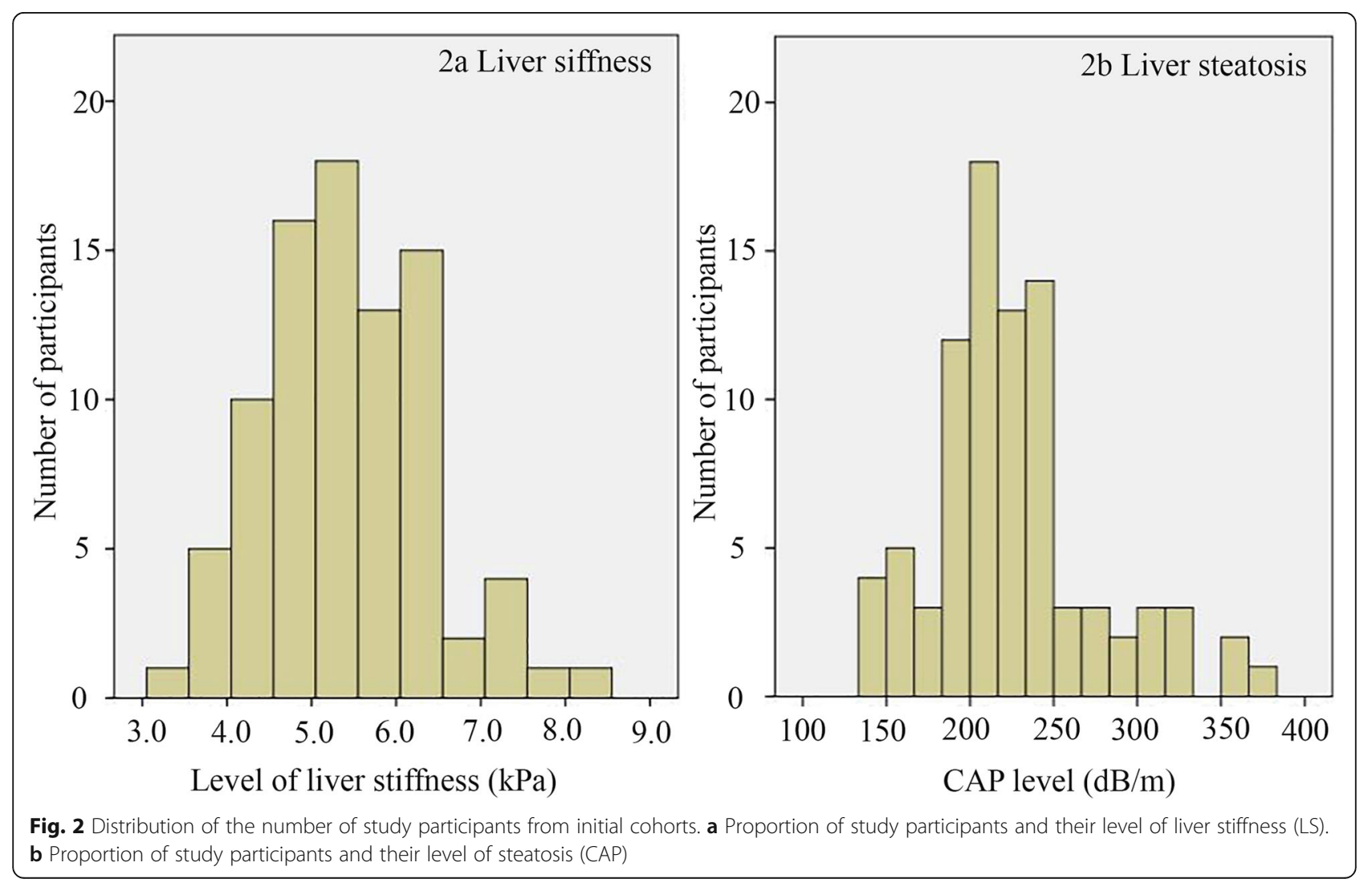


Table 2 Potential factors that may be associated with liver fibrosis and steatosis in the initial cross-sectional cohort

\begin{tabular}{|c|c|c|c|c|c|c|c|c|}
\hline \multirow[t]{3}{*}{ Parameters } & \multicolumn{4}{|c|}{ Factors associated with liver fibrosis } & \multicolumn{4}{|c|}{ Factors associated with liver steatosis } \\
\hline & \multicolumn{2}{|l|}{ Univariate analysis } & \multicolumn{2}{|l|}{ Multivariate analysis } & \multicolumn{2}{|c|}{ Univariate analysis } & \multicolumn{2}{|l|}{ Multivariate analysis } \\
\hline & Pearson Correlation & $P$-value & Pearson Correlation & $P$-value & Pearson Correlation & $P$-value & Pearson Correlation & $P$-value \\
\hline Age & 0.215 & 0.047 & 0.195 & 0.060 & -0.042 & 0.703 & - & - \\
\hline Sex & -0.155 & 0.153 & - & - & -0.237 & 0.028 & -0.161 & 0.062 \\
\hline BLL & -0.086 & 0.430 & - & - & -0.075 & 0.493 & - & - \\
\hline Duration of lead exposure & 0.249 & 0.021 & 0.229 & 0.026 & 0.020 & 0.854 & - & - \\
\hline Waist circumference & 0.220 & 0.076 & - & - & 0.702 & $<0.001$ & 0.524 & $<0.001$ \\
\hline BMI & 0.226 & 0.037 & 0.107 & 0.350 & 0.660 & $<0.001$ & 2.064 & 0.360 \\
\hline Liver steatosis & 0.242 & 0.025 & 0.080 & 0.525 & 1 & - & - & - \\
\hline Liver fibrosis & 1 & - & - & - & 0.242 & 0.025 & 2.155 & 0.656 \\
\hline SGOT & 0.161 & 0.142 & - & - & 0.329 & 0.002 & -0.531 & 0.273 \\
\hline SGPT & 0.332 & 0.002 & 0.317 & 0.002 & 0.566 & $<0.001$ & 0.397 & 0.018 \\
\hline ALP & 0.222 & 0.041 & 0.107 & 0.347 & 0.154 & 0.161 & - & - \\
\hline
\end{tabular}

Abbreviations: BLL blood lead level, BMI body mass index, SGOT serum glutamate oxaloacetate transaminase, SGPT serum glutamate pyruvate aminotransferase, $A L P$ alkaline phosphatase

skin contact (25\%). Once lead is absorbed and enters the bloodstream, it is distributed and deposited in various types of soft tissue in the human body. Lead accumulates in the bone, followed by the liver, kidney, neurons, and spleen [9].

In the blood, $95 \%$ of lead binds to erythrocytes and has a mean half-life of 35 days. There are various ranges of normal BLL depending on an individual's age and environmental exposure to lead. BLLs of $25-40 \mu \mathrm{g} / \mathrm{dl}$ in adults and $5-10 \mu \mathrm{g} / \mathrm{dL}$ in children are considered to be normal reference levels in the nonlead-exposure population, while a BLL of $40-60 \mu \mathrm{g} / \mathrm{dl}$ is an acceptable normal value among occupational lead-exposure workers [10]. The diagnosis of chronic lead poisoning is based on BLL regardless of the presence of signs or symptoms.

To date, there are few studies about hepatotoxicity from lead poisoning. Most of these studies were case reports of participants with acute lead poisoning symptoms and abnormal liver chemistry tests; the ranges of the liver enzymes for SGOT and SGPT were $63-66 \mathrm{mg} /$ $\mathrm{dL}$ and $75-256 \mathrm{mg} / \mathrm{dL}$, respectively [5-7, 11-16]. No liver failure was reported. There were only four analytical studies that focused on hepatotoxicity among occupational lead-exposed workers [4-6, 17]. Every study found that there was a mild elevation of liver enzymes. Two of the studies showed significant differences in the levels of liver enzymes between occupational leadexposed workers and healthy control participants $[6,7]$. However, in the other two studies, there were no differences in the levels of liver enzymes between the people who were exposed to lead and those in the control group [5, 17]. In our study, the majority of participants had normal levels of liver enzymes. However, approximately $20 \%$ of the participants had elevated SGOT and/ or SGPT levels without any known causes. Bilirubin and ALP levels were also normal. These findings were in concordance with previous reports [4-6, 17]. Lead accumulates in the liver among workers who are constantly

Table 3 Comparison of lead-related parameters between pre- and postchelation therapy

\begin{tabular}{|c|c|c|c|c|}
\hline Parameters & $\begin{array}{l}\text { Prechelation } \\
\text { (mean } \pm \text { SD) }\end{array}$ & $\begin{array}{l}\text { Postchelation } \\
\text { (mean } \pm \text { SD) }\end{array}$ & $\begin{array}{l}\text { Mean difference between post- and } \\
\text { prechelation ( } 95 \% \text { confidence interval) }\end{array}$ & $p$-value \\
\hline Blood lead level ( $\mu \mathrm{g} / \mathrm{dL})$ & $81.8 \pm 9.9$ & $56.6 \pm 16.8$ & $-25.2 \pm 13.8(21.9-28.5)$ & $<0.001$ \\
\hline Liver stiffness (kPa) & $5.3 \pm 0.9$ & $4.8 \pm 1.4$ & $-0.5 \pm 1.2(0.2-0.8)$ & 0.001 \\
\hline Steatosis $(\mathrm{dB} / \mathrm{m})$ & $208.6 \pm 31.7$ & $207.0 \pm 45.0$ & $-1.6 \pm 41.0(-8.1-11.4)$ & 0.738 \\
\hline TNF-a (pg/mL) & $371.6 \pm 211.3$ & $215.8 \pm 142.7$ & $-155.8 \pm 137.4(120.9-190.7)$ & $<0.001$ \\
\hline Interleukin-1 $\beta$ (pg/mL) & $29.8 \pm 1.7$ & $25.9 \pm 4.3$ & $-3.8 \pm 3.7(2.9-4.8)$ & $<0.001$ \\
\hline Interleukin-6 (pg/mL) & $46.8 \pm 10.2$ & $35.0 \pm 11.9$ & $-11.8 \pm 10.6(9.1-14.5)$ & $<0.001$ \\
\hline Glutathione $(\mu \mathrm{g} / \mathrm{mL})$ & $3.3 \pm 3.3$ & $13.1 \pm 3.7$ & $9.8 \pm 3.7(10.8-8.9)$ & $<0.001$ \\
\hline
\end{tabular}


Table 4 Degree of correlation between reduced BLL, LS, and CAP for each inflammatory marker studied

\begin{tabular}{|c|c|c|c|c|c|c|}
\hline \multirow{2}{*}{$\begin{array}{l}\text { Inflammatory } \\
\text { markers } \\
\text { affected by } \\
\text { chelation } \\
\text { treatment }\end{array}$} & \multicolumn{2}{|l|}{ Reduced BLL } & \multicolumn{2}{|l|}{ Reduced LS } & \multicolumn{2}{|l|}{ Reduced CAP } \\
\hline & Pearson's Correlation & $p$-value & Pearson's Correlation & $p$-value & Pearson's Correlation & $p$-value \\
\hline TNF-a & 0.212 & 0.919 & -0.014 & 0.909 & -0.237 & 0.048 \\
\hline Interleukin-1 $\beta$ & 0.034 & 0.778 & 0.045 & 0.714 & 0.008 & 0.945 \\
\hline Interleukin-6 & 0.118 & 0.332 & 0.020 & 0.872 & 0.055 & 0.652 \\
\hline Glutathione & -0.100 & 0.410 & -0.030 & 0.802 & -0.079 & 0.517 \\
\hline
\end{tabular}

Abbreviations: BLL blood lead level, $L S$ liver stiffness, CAP controlled attenuation parameters, TNF tumor necrosis factor

exposed to lead. Therefore, we recommend that further investigations exploring chronic toxicity from chronic lead poisoning be conducted.

Our study found that GSH levels were markedly elevated and that BLL decreased after chelation therapy. This might imply that lead depleted antioxidants, which was consistent with findings from animal studies [10, 18]. Lead-induced oxidative stress was the main mechanism of lead poisoning according to the animal models; there was a decrease in GSH reserve and an increase in reactive oxygen species (ROS). Lead inactivates GSH by binding to sulfhydryl groups and inhibits GSH synthesis $[9,18]$. In addition, lead destabilizes the cell membrane by inducing lipid peroxidation, changes the membrane's biophysical properties and causes cell damage [18]. Our study was the first human study that supported findings from animal studies demonstrating that GSH depletion contributed to liver injury in individuals with chronic lead poisoning.

The results from our study supported the systemic inflammation theory. We showed that after chelation therapy, the BLL and the levels of proinflammatory cytokines such as TNF- $\alpha$, IL- $1 \beta$ and IL- 6 were reduced. Lead exposure could enhance the production of various proinflammatory cytokines, such as IL-1 $\beta$, IL-6, IL-8, IFN- $\gamma$ and TNF- $\alpha$. Overall, lead causes tissue damage by inducing inflammation and inhibits anti-inflammatory mechanisms [19-23].

The liver is one of the major organs that accumulates lead. We hypothesized that sustained lead exposure contributed to chronic inflammation, which predisposed individuals to hepatic fibrosis. Histopathological findings from animal experiments [23, 24] and two human case reports of acute lead poisoning with unexplained hepatitis demonstrated extensive microvesicular and macrovesicular steatosis, portal and intralobular lymphocytic infiltrate, disrupted liver parenchymal architecture and pericellular fibrosis [12, 24]. Our study used LS as a noninvasive parameter that represented the degree of liver fibrosis. Although the mean LS in our study was within the normal range, $26.7 \%$ of the participants had
LS values above the significant fibrosis cut-off level. Notably, $82.6 \%$ of the participants with significant fibrosis had nonsevere steatosis; thus, significant liver fibrosis might be a consequence of lead poisoning. Our study found that the duration of lead exposure was the major factor associated with the development of liver fibrosis. This finding supported our hypothesis that liver injury occurred as a result of chronic lead poisoning.

After chelation therapy, we found that the degree of LS and levels of inflammatory cytokines were significantly reduced and that there was an increase in GSH. These findings suggested that liver fibrosis was associated with lead poisoning. Although the change in the degree of LS was not significantly altered in proportion to a change in any single biomarker, we postulated that each cytokine exerted small effects in concert, rather than a single cytokine resulting in hepatic fibrosis.

Evidently, chronic liver inflammation from chronic lead poisoning not only leads to hepatic fibrosis but also induces various pathways that contribute to the development of hepatic steatosis. Animal studies have revealed that lead-intoxicated rats had altered gene expression of hepatic enzymes involved in cholesterol and triglyceride homeostasis ${ }^{7,25-27}$. Few studies have found significant hypertriglyceridemia and hypercholesterolemia among lead-exposed workers ${ }^{28,} 29$ with scant histological reports of macrovesicular steatosis [12]. The mean CAP in our study was $225.1 \pm 49.3 \mathrm{~dB} / \mathrm{m}$, which was considered to indicate mild steatosis (S1). Notably, $54.7 \%$ of our participants had significant steatosis. However, we did not find a significant correlation between the degree of steatosis and lead-associated parameters, such as the duration of exposure and BLL. Obesity might overcome the effects of chronic lead poisoning. We observed a strong significant correlation between the degree of steatosis and $\mathrm{BMI}$ as well as WC.

Regarding the change in the degree of liver steatosis, we did not find a significant reduction in the level of CAP after treatment. In terms of inflammatory marker analysis, only TNF- $\alpha$ levels changed and were significantly negatively correlated with CAP changes. It should 
be noted that the mean prechelation CAP level was rather low and within the normal reference range. It is possible that the sample size was too small to allow for the detection of a change in CAP after therapy. Thus, we cannot confidently conclude that there was no relationship between lead toxicity and steatosis.

Our study has some limitations. First, the lack of a control group in our study might compromise the strength of the conclusion of the efficacy of chelation therapy in regard to changes in the degree of liver fibrosis, levels of inflammatory mediators and GSH. Regarding liver fibrosis and steatosis detection, we did not use the gold standard of histopathology to detect liver fibrosis and steatosis. Due to ethical and safety concerns, we opted to use a noninvasive technique, FibroScan ${ }^{\circ}$, which has been validated by other investigators. FibroScan ${ }^{\circ}$ has shown good accuracy in evaluating the degree of fibrosis and can even replace liver biopsy ${ }^{30}$. Another limitation was that the chelation regimen might be insufficient because the mean posttreatment BLL was still above the normal level, and the follow-up time might have been too short to detect any change after treatment.

\section{Conclusion}

Continuous exposure to lead has an adverse effect on the liver. The duration of lead exposure was significantly correlated with the degree of fibrosis. Lead might deplete antioxidants and increase the systemic inflammatory response. Treatment with chelation was associated with increased levels of GSH and decreased levels of proinflammatory cytokines such as TNF- $\alpha$, IL- $1 \beta$ and IL- 6 . Hence, chelation therapy could potentially reduce the degree of LS.

\section{Supplementary information}

Supplementary information accompanies this paper at https://doi.org/10. 1186/s12876-020-01386-w.

Additional file 1: Supplementary Table 1. Correlation analyses between LS and CAP in the prospective intervention cohort

\section{Abbreviations}

GSH: Glutathione; LS: Liver stiffness; TNF: Tumor necrosis factor; IL: Interleukin; BLL: Blood lead level; US: United States; OSHA: Occupational Safety and Health Administration; HBV: Hepatitis B virus; HCV: Hepatitis C virus; NAFL D: Nonalcoholic fatty liver disease; WC: Waist circumference; CAP: Controlled attenuation parameters; NCEP ATP: National Cholesterol Education Program Adult Treatment Panel; TE: Transient elastography; ULN: Upper limit normal; SGPT: Serum glutamate-pyruvate transaminase; ALP: Alkaline phosphatase; BMI: Body mass index; SGOT: Serum glutamic-oxaloacetic transaminase

\section{Acknowledgments}

We thank Wasan Panyasang, MSc, the Research Affairs of the Faculty of Medicine, Chulalongkorn University, Bangkok, for biomedical statistical consultation.

\section{Authors' contributions}

$\pi$ designed the study, performed the research, analyzed data, and wrote the full manuscript. RC designed the study and revised the manuscript for final submission. PP designed the study, wrote the manuscript and revised the manuscript for final submission. DW collected specimens, contributed to laboratory interpretation, and revised the final manuscript for submission. All authors have read and approved the manuscript.

\section{Funding}

This study received funding from the Grant for International Research Integration: Chula Research Scholar and the Ratchadapiseksompotch Fund, Faculty of Medicine, Chulalongkorn University (grant number RA61/120). The funders had no role in study design, data collection and analysis, decision to publish, or preparation of the manuscript.

\section{Availability of data and materials}

The datasets used and/or analyzed during the current study are available from the corresponding author on reasonable request.

\section{Ethics approval and consent to participate}

This study was approved by the Institutional Review Board of the Faculty of Medicine, Chulalongkorn University (IRB. Number 297/61). All participants provided written consent prior to study enrollment.

\section{Consent for publication}

Not applicable.

\section{Competing interests}

The authors declare that they have no competing interests.

\section{Author details}

${ }^{1}$ Division of Gastroenterology, Department of Medicine, Faculty of Medicine, Chulalongkorn University and King Chulalongkorn Memorial Hospital, Bangkok 10330, Thailand. ${ }^{2}$ Center of Excellence for Innovation and Endoscopy in Gastrointestinal Oncology, Division of Gastroenterology, Department of Medicine, Faculty of Medicine, Chulalongkorn University, Bangkok 10330, Thailand. ${ }^{3}$ Alternative and Complementary Medicine for Gastrointestinal and Liver Diseases Research Unit, Department of Physiology, Faculty of Medicine, Chulalongkorn University, Bangkok 10330, Thailand.

Received: 9 November 2019 Accepted: 15 July 2020

Published online: 08 August 2020

\section{References}

1. Kianoush S, Sadeghi M, Balali-Mood M. Recent advances in the clinical Management of Lead Poisoning. Acta Med Iran. 2015;53(6):327-36.

2. Ericson BLP, Taylor MP, Frostad J, Caravanos J, Keith J, Fuller R. The global burden of Lead toxicity attributable to informal used Lead-acid battery sites. Ann Glob Health. 2016;82(5):686-99.

3. Ab Latif Wani AA, Usmani JA. Lead toxicity: a review. Interdiscip Toxicol. 2015;8(2):55-64

4. Mitra P, Sharma S, Purohit P, Sharma P. Clinical and molecular aspects of lead toxicity: an update. Crit Rev Clin Lab Sci. 2017;54(7-8):506-28.

5. Bhagwat VR, Patil AJ, Patil JA, Sontakke AV. Occupational lead exposure and liver functions in battery manufacture workers around Kolhapur (Maharashtra). Al Ame en J Med Sci. 2008;1(1):2-9.

6. Dioka CE, Orisakwe OE, Adeniyi FA, Meludu SC. Liver and renal function tests in artisans occupationally exposed to lead in mechanic village in Nnewi, Nigeria. Int J Environ Res Public Health. 2004;1(1):21-5.

7. Dongre NN, Suryakar AN, Patil AJ, Rathi DB. Occupational Lead Exposure In Automobile Workers In North Karnataka (India): Effect On Liver And Kidney Functions. Al Ameen J Med Sci. 2010;3(4):284-92.

8. Vanduangden KCR, Thanapirom K, Sonsiri K, Treeprasertsuk S. Prevalence of nonalcoholic fatty liver disease (NAFLD) diagnosed by controlled attenuation parameter with transient elastography in subjects with and without metabolic syndrome. Chula Med J. 2017;61(4):483-95.

9. Kim HC, Jang TW, Chae HJ, Choi WJ, Ha MN, Ye BJ, Kim BG, Jeon MJ, Kim SY, Hong YS. Evaluation and management of lead exposure. Ann Occup Environ Med. 2015;27:30.

10. OSHA Instruction CPL 2-2.58. 29 CFR 1926.62, Lead Exposure In Construction; Interim Final Rule-Inspection and Compliance Procedures, Office of Health Compliance Assistance; 1993. https://www.osha.gov/ enforcement/directives/cpl-02-02-058. Accessed 13 Dec 2019. 
11. Marginean CO, Melit LE, Moldovan H, Lupu W, Marginean MO. Lead poisoning in a 16-year-old girl: a case report and a review of the literature (CARE compliant). Medicine (Baltimore). 2016;95(38):e4916.

12. Verheij J, Voortman J, van Nieuwkerk CM, Jarbandhan SV, Mulder CJ Bloemena E. Hepatic morphopathologic findings of lead poisoning in a drug addict: a case report. J Gastrointestin Liver Dis. 2009;18(2):225-7.

13. Menezes G, D'Souza HS, Venkatesh T. Chronic lead poisoning in an adult battery worker. Occup Med (Lond). 2003;53(7):476-8.

14. Grasso LIA, Blattner CMR, Short ET, Downs MJW. Severe Systemic Lead Toxicity Resulting From Extra-Articular Retained Shrapnel Presenting as Jaundice and Hepatitis: A Case Report and Review of the Literature. Int J AMSUS. 2017;182(3):e1843-e8.

15. Pagliuca A, Mufti GJ, Baldwin D, Lestas AN, Wallis RM, Bellingham AJ. Lead poisoning: clinical, biochemical, and haematological aspects of a recent outbreak. J Clin Pathol. 1990;43(4):277-81.

16. Cullen MR, Robins JM, Eskenazi B. Adult inorganic lead intoxication: presentation of 31 new cases and a review of recent advances in the literature. Medicine (Baltimore). 1983;62(4):221-47.

17. Onyeneke ECOE. Effect of occupational exposure to lead on liver function parameters. Int J Pharm Med Sci. 2016;6:15-9.

18. Flora G, Gupta D, Tiwari A. Toxicity of lead: a review with recent updates. Interdiscip Toxicol. 2012:5(2):47-58.

19. Dietert RR, Lee JE, Hussain I, Piepenbrink M. Developmental immunotoxicology of lead. Toxicol Appl Pharmacol. 2004;198(2):86-94.

20. Hsiao CL, Wu KH, Wan KS. Effects of environmental lead exposure on Thelper cell-specific cytokines in children. J Immunotoxicol. 2011;8(4):284-7.

21. Garcia-Leston J, Roma-Torres J, Mayan O, Schroecksnadel S, Fuchs D, Moreira AO, Pasaro E, Mendez J, Teixeira JP, Laffon B. Assessment of immunotoxicity parameters in individuals occupationally exposed to lead. J Toxicol Environ Health A. 2012;75(13-15):807-18.

22. Dobrakowski M, Kasperczyk A, Pawlas N, Birkner E, Hudziec E, Chwalinska E, Kasperczyk S. Association between subchronic and chronic lead exposure and levels of antioxidants and chemokines. Int Arch Occup Environ Health. 2016;89(7):1077-85.

23. Chang WJ, Joe KT, Park HY, Jeong JD, Lee DH. The relationship of liver function tests to mixed exposure to lead and organic solvents. Ann Occup Environ Med. 2013;25(1):5.

24. Jarrar BM, Taib NT. Histological and histochemical alterations in the liver induced by lead chronic toxicity. Saudi J Biol Sci. 2012;19(2):203-10.

\section{Publisher's Note}

Springer Nature remains neutral with regard to jurisdictional claims in published maps and institutional affiliations.

Ready to submit your research? Choose BMC and benefit from:

- fast, convenient online submission

- thorough peer review by experienced researchers in your field

- rapid publication on acceptance

- support for research data, including large and complex data types

- gold Open Access which fosters wider collaboration and increased citations

- maximum visibility for your research: over $100 \mathrm{M}$ website views per year

At $\mathrm{BMC}$, research is always in progress.

Learn more biomedcentral.com/submissions 